\title{
Injustiças no cotidiano escolar: percepções de membros de uma escola pública
}

\author{
Injustiças no cotidiano escolar
}

\author{
Thaise Beluci \\ Alessandra de Morais Shimizu
}

\begin{abstract}
Resumo
Embasada nas teorias piagetiana e kohlberguiana sobre o desenvolvimento de julgamento moral, esta pesquisa teve como objetivo identificar as principais ocorrências de injustiça no cotidiano de uma escola pública de ensino fundamental e médio do oeste paulista e comparar as percepções dos diferentes membros da escola em pauta. A coleta de dados consistiu na aplicação de um questionário em 156 alunos, 39 pais de alunos, 15 professores e 1 I funcionários, perfazendo um total de $22 \mathrm{I}$ participantes. Os dados foram analisados e comparados conforme o papel exercido por categoria do participante na escola investigada. Os resultados demonstraram que a escola é concebida como um ambiente injusto por seus membros, no entanto, os agentes que possibilitam ações consideradas injustas (professores, direção/coordenação, alunos, pais, polícia e sociedade) são percebidos de maneira diferente de acordo com o papel desempenhado pelo membro da comunidade escolar.

Palavras-chave: desenvolvimento moral; aprendizagem; ambiente escolar.
\end{abstract}

\section{Injustice in the daily school life: perceptions of the members of a public school}

\begin{abstract}
Based on piagetian and kohlbergian theory about the development of moral judgment, this research had as its objective to identify the main injustice occurrence in the daily life of an Elementary and Secondary Public School in the West of Sao Paulo State, and compare the different member's perceptions of the mentioned school. The data collection was constituted of a questionnaire application based on the following sample: 156 students, 39 student parents, 15 teachers and II staff members, bringing it up to a total of 221 participants. The data were analyzed and compared according to the role performed by each participating category in the investigated school. The results showed that the school is seen as an unjust environment by its members, however, the agents that enable actions considered unjust (teachers, principal's office/teacher co-ordination, students, parents, police and community) are perceived in a different way according to the role performed by each school community member.
\end{abstract}

Keywords: moral development; learning; school environment.

\section{Injusticias en el cotidiano escolar: percepciones de miembros de una escuela pública}

\section{Resumen}

Con base en las teorías piagetiana y kohlberguiana sobre el desarrollo del juicio moral, esta investigación tuvo como objetivo identificar los casos principales de injusticia en el cotidiano de una escuela pública de enseñanza primaria y secundaria del oeste paulista, y comparar las percepciones de los diferentes miembros de esa escuela. La cosecha de datos consistió en la aplicación de un cuestionario en 156 alumnos, 39 padres de alumnos, 15 profesores y II funcionarios, totalizando 22 I participantes. Los datos fueron analizados y comparados de acuerdo al papel ejercido por categoría del participante en la escuela investigada. Los resultados demostraron que la escuela es concebida por sus miembros como un ambiente injusto, y que por otro lado, los agentes que posibilitan acciones consideradas injustas (profesores, dirección/coordinación, alumnos, padres, policía y sociedad) son percibidos de forma diferente de acuerdo con el papel desempeñado por el miembro de la comunidad escolar.

Palabras clave: desarrollo moral; aprendizaje; ambiente escolar. 


\section{Introdução}

Atualmente, frente a uma crise de valores, violência, corrupção e desigualdade na nossa sociedade brasileira, refletido no contexto educacional por meio de problemas relacionados à violência, indisciplina e desinteresse, há uma grande preocupação com o aspecto moral da educação e sua consideração tanto no meio acadêmico como nas propostas sociais. Por um lado, as novas propostas que têm como principais representantes os Parâmetros Curriculares Nacionais para o Ensino Fundamental e Médio (Brasil, 1997, 1998) - assim como diferentes pesquisadores (Araújo, 2002, 2003, 2004; Buxarrais, 1997; Menin, 2000, 2002a, 2002b; Puig, 1998; Shimizu, 1998; Shimizu e cols., 2003) defendem que cabe à escola participar da formação moral de seus alunos, atuando dentro dos princípios democráticos visto que é mais um meio social na vida dos indivíduos.

Por outro lado, constata-se que a implantação dessas propostas é, ainda, um grande desafio e envolve uma diversidade de fatores que, segundo Araújo (2002), perpassam desde os conteúdos escolares e a metodologia das aulas até os valores dos membros da comunidade escolar e a maneira como as relações interpessoais se dão, dentre outros fatores.

Concorda-se aqui com Araújo (2002), ao considerar que um fator relevante, mas não único, da ocorrência da indisciplina na escola seja os tipos de relações interpessoais estabelecidas entre os diferentes membros da comunidade escolar. Com base em Piaget (1932/ 1994) e Kohlberg (1976/1992), supõese que o tipo de respeito presente nessas relações e - fato dessas relações serem consideradas justas ou injustas pelos atores nelas envolvidos são fatores importantes para a direção em que se dá o desenvolvimento moral dos mesmos, e, conseqüentemente, para a forma como eles se relacionam com as normas e regras escolares. Como o apoio teórico está nos dois autores referidos, são acrescidas aqui as informações mais pertinentes de suas proposições.

Na obra O Juízo Moral na Criança, publicada em 1932, ao investigar o desenvolvimento do julgamento moral na criança, Piaget (1932/1994) distinguiu duas morais relacionadas a dois tipos de respeito: a moral da coação ou da heteronomia, na qual a regra é exterior ao indivíduo, proveniente de um adulto e acompanhada do respeito unilateral; e a moral da cooperação ou da autonomia, na qual a regra provém do indivíduo, é interior a ele e apresenta como guia o respeito mútuo. $O$ ideal é que, segundo esse autor, com o passar dos anos, a criança passe da heteronomia para a autonomia moral.

Relacionado com esses dois tipos de moral, Piaget (1932/1994) descreveu três períodos no desenvolvimento da justiça na criança. $O$ primeiro, em que a justiça está completamente subordinada à autoridade adulta, caracterizado pela não-diferenciação do justo e do injusto com o dever e a desobediência. A criança, nessa época, considera injustas apenas as condutas em que não são seguidas as regras ordenadas pelos adultos, prevalecendo o respeito unilateral e a heteronomia da lei. No segundo período são identificados o igualitarismo e o desenvolvimento progressivo da autonomia, além do predomínio da busca igualdade sobre a autoridade. E o terceiro período, em que o igualitarismo cede lugar à eqüidade, consiste em uma relação baseada não sobre a igualdade, mas sobre a situação real de cada indivíduo no que diz respeito a necessidades e capacidades.

Piaget (1932/1994) investigou, também, exemplos de injustiças, segundo as crianças, e percebeu a existência de quatro tipos de respostas: condutas contrárias às ordens e a fazer algo proibido, condutas contrárias às regras do jogo e à igualdade, e injustiças referentes à sociedade adulta, como injustiças econômicas, políticas e sociais.

Conforme Piaget (1930/1996, 1932/1994), certas experiências morais orientarão a criança para uma ou outra direção. A autoridade adulta constitui um momento necessário na evolução moral da criança, mas não é suficiente para construir o senso de justiça, que só se desenvolve com a cooperação e o respeito mútuo. Dessa forma, a escola deve ser um local em que a criança possa vivenciar a moralidade, impulsionando a construção de personalidades autônomas aptas à cooperação.

Com base nessa concepção, Piaget (1930/1996) defende o método ativo de educação moral, que se 
baseia na idéia de que os conteúdos devem ser (re)descobertos pelas próprias crianças, através de uma investigação e atividade espontâneas, ao invés de serem impostos de fora. Nesse método, a educação moral não constitui uma matéria à parte, e sim compõe todas as disciplinas, de maneira transversal, como também é proposto nos Parâmetros Curriculares Nacionais. É fundamental, ainda, que a classe forme uma sociedade real, isto é, uma associação que envolva trabalho comum entre seus membros, na qual possam organizar suas próprias leis disciplinares bem como àqueles que terão a função de governar e repreender quando necessário. Em suma, o método ativo busca sempre não impor pela autoridade aquilo que a criança possa descobrir por si mesma e, conseqüentemente, criar um meio social infantil onde a criança possa realizar as experiências desejadas (Piaget, 1930/1996).

No campo do Desenvolvimento Moral deve-se destacar, também, a contribuição do psicólogo norteamericano Lawrence Kohlberg que, além de dar prosseguimento aos estudos piagetianos sobre a evolução da moral na criança, realizando pesquisas interculturais, procurou, também, inserir no cotidiano escolar uma Educação Moral que possibilitasse graus de consciência moral cada vez mais elevados nos jovens.

Para Kohlberg (1976/1992), a estrutura essencial da moralidade é a justiça, e tem seu desenvolvimento por meio de seis estágios morais, agrupados em três grandes níveis da moralidade: o pré-convencional, o convencional e o pós-convencional.

No primeiro nível moral, o pré-convencional, a criança percebe a existência das regras sociais, do bem e do mal. No entanto, para ela o valor moral está, ainda, localizado nos acontecimentos externos e baseado no poder físico de quem estipula a regra moral. O nível convencional implica em conformidade e manutenção das normas mediante a identificação com a ordem social ajustada a fim de ser preservada a lealdade para com a família, o grupo ou a nação. $O$ nível pós-convencional é caracterizado pelo entendimento e aceitação das normas da sociedade, com base em princípios morais gerais que transcendem essas regras. Nesse patamar do desenvolvimento moral, o indivíduo tem o seu "eu" diferenciado das normas e expectativas, definindo seus valores de forma autônoma e justa.

Kohlberg (1976/1992) defende, ainda, a idéia de que o contato do indivíduo com um estágio imediatamente superior ao próprio impulsiona a evolução moral, visto que os sujeitos tendem a assimilar o raciocínio moral a partir desse estágio posterior. Esse movimento dá-se por meio de uma reflexiva organização que surge das contradições percebidas na estrutura de seu estágio atual; assim, as experiências de conflito cognitivo podem ser eliciadas pela exposição de situações que suscitem contradições internas nas estruturas do pensamento moral. A partir desse princípio básico, ele elaborou dois tipos de programa educacional: a discussão de dilemas morais em grupos e a construção de comunidades justas.

O Programa de Educação Moral, baseado na discussão de dilemas morais, visava promover o desenvolvimento moral, gerando um confronto de opiniões entre os participantes, o que originava um conflito cognitivo, que por sua vez, conduzia a uma maior maturidade de julgamento moral. Essa técnica requer a formação de grupos de 10 a 12 sujeitos, que se encontrem em diferentes estágios, orientados por um coordenador para debater dilemas morais. O papel do coordenador é engajar os participantes na discussão, examinar os pontos de vista conflitantes, para que, posteriormente, uma solução seja proposta pelo próprio grupo (Biaggio, 2002).

No entanto, Kohlberg e seus colaboradores (Kohlberg, Power \& Higgins, 1989/1997) sentiram a necessidade de introduzir uma nova estratégia de Educação Moral, com a qual procurassem eliminar a artificialidade dos dilemas morais e de suas soluções pelo debate, substituindo-os pela discussão de situações práticas do cotidiano, que necessitassem de soluções e ações morais verdadeiras.

Segundo Kohlberg, Power e Higgins (1989/1997) e Biaggio (1997, 2002), o método em questão, denominado "Comunidade Justa", dentre outras experiências, foi colocado em prática em 1974, e teve a duração de cinco anos, em uma escola pública denominada Cluster, localizada dentro da Cambridge High School. Essa escola funcionava, de forma geral, da seguinte maneira: uma vez por semana, alunos e profes- 
sores realizavam a reunião da comunidade, na qual discutiam as regras, bem como a manutenção das mesmas, cada um tinha direito a um voto e predominava a decisão votada pela maioria; na véspera da reunião, acontecia o encontro dos grupos conselheiros, pequenos grupos que introduziam as questóes que necessitavam de discussão na reunião da comunidade; quando um ato necessitava de punição, a mesma era estudada por uma comissão de alunos e professores, considerando que ambos tinham os mesmos direitos e privilégios, a sanção aplicada tinha o intuito de reafirmar a autoridade e reparar os danos causados à comunidade.

De acordo com Biaggio (2002), a "Comunidade Justa" visa a uma aprendizagem de participação democrática, aumento do senso de responsabilidade, motivação para o trabalho escolar, cidadania e autoestima. Numa comunidade democrática, professores e alunos são membros iguais, têm os mesmos direitos e deveres, pois compartilham de um projeto comum, a construção de uma comunidade justa, o que envolve estabelecer regras para tal. Conseqüentemente, os professores devem estar dispostos a trabalhar de acordo com esses procedimentos. Isso serve também para os alunos. Há, ainda, evidências de que esse método pode levar a estágios elevados da moral e influenciar no tratamento entre os membros.

De acordo com Menin (2003), não obstante a experiência de Kohlberg e as idéias sobre escolas democráticas sejam conhecidas, esse tipo peculiar de organização não condiz com o contexto escolar atual visto que, muitas vezes, conforme demonstram as pesquisas de Carbone e Menin (2004) e Shimizu e cols. (2003), a escola aparece aos olhos dos alunos como espaço de injustiças diversas e freqüentes, sendo sua realidade muito diferente de uma comunidade justa.

A pesquisa de Shimizu e cols. (2003) foi realizada com 276 alunos de $4^{\text {a }}$ série do ensino fundamental e de I ${ }^{\text {a }}$ série do ensino médio, do ensino público e particular, do interior paulista. Os autores tiveram como objetivo identificar as concepções dos alunos sobre injustiças que ocorriam na escola e na sala de aula. Para tanto, um questionário com questões sobre definição de injustiça, identificação de injustiças na esco- la e na sala de aula e uma escala com 35 situações de injustiça foram utilizados. De forma geral, em ambas as séries, os casos de injustiça mais apontados referiram-se às ocorrências de injustiças cometidas pelos alunos entre si, dos alunos aos professores e destes aos alunos.

Carbone e Menin (2004) analisaram duas pesquisas que realizaram com alunos do ensino fundamental e médio de escolas públicas e particulares do município de Presidente Prudente, nas quais se buscou investigar como os alunos representavam situações de injustiça na escola bem como seus agentes e os tipos de ações que cometiam. Os dados examinados procederam de respostas obtidas por meio de um questionário aplicado, em 1999, em 480 alunos da $8^{\mathrm{a}}$ série do ensino fundamental e $\mathrm{I}^{\mathrm{a}}$ série do ensino médio e de respostas de 73 alunos da $5^{a}$ série do ensino fundamental, obtidas em questões sobre injustiça na escola, aplicadas em 2003. Comparando os dois conjuntos de dados, conclui-se que em nenhuma das séries a escola aparece como uma "comunidade justa" e prevalecem como agentes de injustiças, primeiramente, o professor perante seus alunos e, em segundo lugar, os alunos entre eles mesmos.

Inserida nessa problemática, assim como inúmeras outras escolas brasileiras, uma escola estadual de ensino fundamental e médio, de uma cidade do oeste paulista, tem enfrentado sérios problemas de indisciplina, desinteresse e depredação por parte dos alunos e de desmotivação e insatisfação pelo corpo docente e administrativo. Esse quadro impulsionou, então, a realização deste estudo, que teve como objetivos: identificar as principais ocorrências de injustiça no cotidiano da escola em pauta e comparar as percepções de seus diferentes membros.

\section{Método}

\section{Participantes}

A presente pesquisa foi realizada em uma escola pública de ensino fundamental (EF) e médio (EM) da $5^{\mathrm{a}}$ série do $E F$ ao $3^{\circ}$ ano do $E M$ - do oeste paulista, nos meses de outubro e novembro de 2005. Partici- 
param da pesquisa 156 alunos $(20,2 \%$ do total de alunos matriculados na escola), 39 pais de alunos (5\% do total de um dos pais dos alunos matriculados na escola), 15 professores ( $42 \%$ do total de professores) e I I funcionários (84,6\% do total de funcionários), somando 221 participantes.

\section{Critério de Seleção}

Dos 156 alunos que responderam ao questionário, $57,7 \%$ é do sexo feminino e $42,3 \%$ do sexo masculino. É de $56,4 \%$ a porcentagem de participantes que cursa $\circ$ ensino fundamental (de $5^{\mathrm{a}}$ a $8^{\mathrm{a}}$ série do $E F)$ e de $43,6 \% \%$ que freqüenta o ensino médio. Em relação à faixa etária dos discentes, $54,5 \%$ possui de 10 a 14 anos, $41,5 \%$ de 15 a 20 anos e $4,5 \%$ de 21 a 35 anos.

Quanto aos 15 docentes participantes, o sexo predominante foi o feminino, sendo $60 \%$ dos professores pesquisados mulheres e $40 \%$, homens. No caso da idade, a maioria tem mais de 35 anos (60\%) e $26,7 \%$ têm entre 21 e 35 anos. Ainda, 13,3\% deles se abstiveram de responder essa questão. No que se refere à escolaridade, todos os professores alegaram possuir ensino superior completo. No que diz respeito ao tempo de magistério, a maioria deles possui mais de 10 anos (53,3\%), seguido por aqueles que possuem entre 6 e 10 anos (26,7\%) e por último, os professores que trabalham de 0 a 5 anos nessa profissão (20\%).

No que tange à caracterização da amostra que envolve os funcionários (II participantes), 63,6\% é do sexo feminino e $36,4 \%$ do masculino. No caso da idade todos os funcionários que responderam a essa questão têm mais de 35 anos. A questão da escolaridade apontou para uma prevalência do ensino médio $(63,6 \%)$, com um percentual reduzido daqueles que atingiram o nível superior (I8,2\%) ou que cursaram o ensino fundamental apenas.

A distribuição do sexo na categoria pais foi a mais contrastante dentre todas as outras categorias, pois a maioria esmagadora dos participantes foi de mães de alunos, portanto, representantes do sexo feminino $(84,6 \%)$. Os pais, que designam o sexo masculino, atingiram uma porcentagem significativamente menor ( $15,4 \%)$. Quanto à idade, há $35,9 \%$ dos pais na faixa de 21 a 35 anos sendo que, a maioria deles, $(56,4 \%)$ tem mais de 35 anos; foram $7,7 \%$ deles que não responderam a essa pergunta. $\mathrm{Na}$ questão da escolaridade, $46,2 \%$ estudou até o ensino médio, $43,6 \%$ até o ensino fundamental e 10,3\% cursaram o ensino superior.

$\mathrm{Na}$ questão que abordava a profissão dos pais foi verificado que a maior parte deles é "do lar", seguido pelos trabalhadores de produção, ajudantes e auxiliares. A minoria exerce ocupações de nível médio, auxiliares de administração e vendas e cargos de assistências de chefias, analistas e profissionais de nível superior. Ainda, alguns são aposentados ou já faleceram. Na questão que abordava a profissão dos pais foi verificado que a maior parte deles $(33,3 \%)$ é "do lar", seguido pelos $30,8 \%$ de trabalhadores de produção, ajudantes e auxiliares. Com 17,9\% ficaram os trabalhadores que exercem ocupações de nível médio, auxiliares de administração e vendas. Os cargos de assistências de chefias, analistas e profissionais de nível superior somaram 5,1\%. E, ainda, $12,8 \%$ dos pais participantes são aposentados.

\section{Material}

Para a coleta de dados foi elaborado um questionário, com base nas pesquisas de Carbone e Menin (2004) e Shimizu e cols. (2003), já descritas no presente texto, que investigaram as concepções de injustiça em alunos de escolas públicas e particulares. No questionário em pauta, foi apresentada uma questão que inquiria os respondentes sobre a freqüência com que diversas situações de injustiça ocorriam na escola em estudo. A questão era a seguinte: "Em cada situação que apresentaremos logo abaixo marque com um X se: Nunca aconteceu /Aconteceu uma vez; Aconteceu algumas vezes; e Aconteceu várias vezes/Acontece sempre". Foi apresentado um quadro com um total de 39 situações, cada uma delas relacionada a agentes específicos, causadores de injustiça e a públicosalvos da injustiça. Os agentes e os públicos-alvos eram: o professor como agente de injustiça em relação ao aluno; os alunos entre si; a sociedade e governo à educação; a direção/coordenação em relação aos alunos; a polícia para com os alunos; os alunos aos professores; os pais com a escola; a escola para com os pais 
dos alunos; o uso de drogas lícitas ou ilícitas na escola, e os alunos em relação à escola.

Por meio do agrupamento dessas situações, foi verificada a freqüência com que esses agentes eram mencionados como causadores de acontecimentos injustos. Essa freqüência consistiu na soma entre as respostas "Aconteceu algumas vezes" e "Aconteceu várias vezes/Acontece sempre” por categoria participante.

\section{Procedimento}

A pesquisa cumpre os aspectos éticos dispostos na Resolução 196/96 do Conselho Nacional de Saúde (BRASIL, 1996) e foi autorizada, formalmente, pelo Diretor da escola, mediante assinatura de carta de autorização. Ainda, cada participante assinou, espontaneamente, um Termo de Consentimento Livre Pósinformação, no qual estavam explicitados os objetivos da pesquisa, a garantia do anonimato da identidade do participante e a forma de utilização dos dados provenientes da investigação. No caso dos alunos menores de 18 anos, o Termo de Consentimento foi assinado pelo aluno e seu respectivo responsável legal. O Projeto da presente pesquisa foi analisado pelo Comitê de Ética em Pesquisa da Faculdade de Ciências da Saúde de Garça (FASU), recebendo parecer favorável à sua realização.

A aplicação dos questionários nos alunos foi precedida por uma visita à escola para explicar os propósitos da pesquisa e distribuir os Termos de Consentimento Livre Pós-Informação, para que fossem assinados por seus respectivos pais e/ou responsáveis legais. Em dois dias posteriores foi efetuado o recolhimento daqueles Termos assinados. Somente os alunos que devolveram uma via do Termo assinada participaram da pesquisa. Esses alunos foram chamados em suas respectivas classes e levados até o anfiteatro da escola para que respondessem ao questionário. Os funcionários foram abordados individualmente durante seus respectivos horários de trabalho, para que respondessem ao questionário. A maioria dos professores preencheu $\circ$ questionário durante 0 HTPC (Horário de Trabalho Pedagógico Coletivo), que consiste em reuniões semanais coletivas realizadas na escola pelos professores da rede pública de ensino estadual paulista, e tem como objetivo avaliar e discu- tir temas relacionados ao contexto educacional. Quanto ao restante dos professores, ausentes no HTPC, foram realizadas abordagens individuais na própria escola. Os pais de alunos foram abordados na reunião de pais realizada pela escola. Aqueles que concordaram em participar da pesquisa, por conta do tempo exíguo, levaram os questionários para devolução posterior, o que ocorreu em número escasso. Diante disso, a pesquisadora se dirigiu à casa de outros pais, selecionados aleatoriamente, convidando-os a participarem da pesquisa. Nesse caso, os pais que consentiam ficavam com o questionário e, posteriormente, a pesquisadora passava para recolhê-los.

\section{Resultados e Discussão}

Os dados a seguir expressam, segundo a percepção dos participantes, as principais ocorrências de injustiças no cotidiano da escola investigada. Podem ser visualizados, por meio da Figura I, os dados já agrupados, voltados, no entanto, para a qualidade da discussão dos resultados e a título de ilustração, muitas vezes, são referidas algumas situações específicas que não são demonstradas na figura, mas que integram o agrupamento em foco.

Conforme é demonstrado na Figura I, a escola estudada pode ser considerada como um espaço de injustiças e, muitas vezes, a percepção que tem das situações injustas diverge, expressivamente, entre os membros da comunidade escolar. Esse dado é confirmado, especialmente, naquelas categorias em que o Teste do Qui-quadrado apresentou significância, demonstrado no gráfico com o asterisco $\left(^{*}\right)$ e apresentado, com o respectivo valor, no texto a seguir.

O primeiro item da Figura I aponta as injustiças do professor ao aluno $\left(\chi^{2}=16,62 ; p<0,05\right)$. Na maioria dessas situações, os membros que mais delatam essas circunstâncias são os alunos $(76,2 \%)$ e os pais de alunos $(76,9 \%)$. Nota-se, assim, que eles reconhecem muito mais esses tipos de situações do que os próprios professores $(46,7 \%)$, no caso, agentes das mesmas, e os funcionários (45,5\%). As situações em que essas divergências se apresentam mais salientes são: professor punir toda sala de aula por causa de mau 


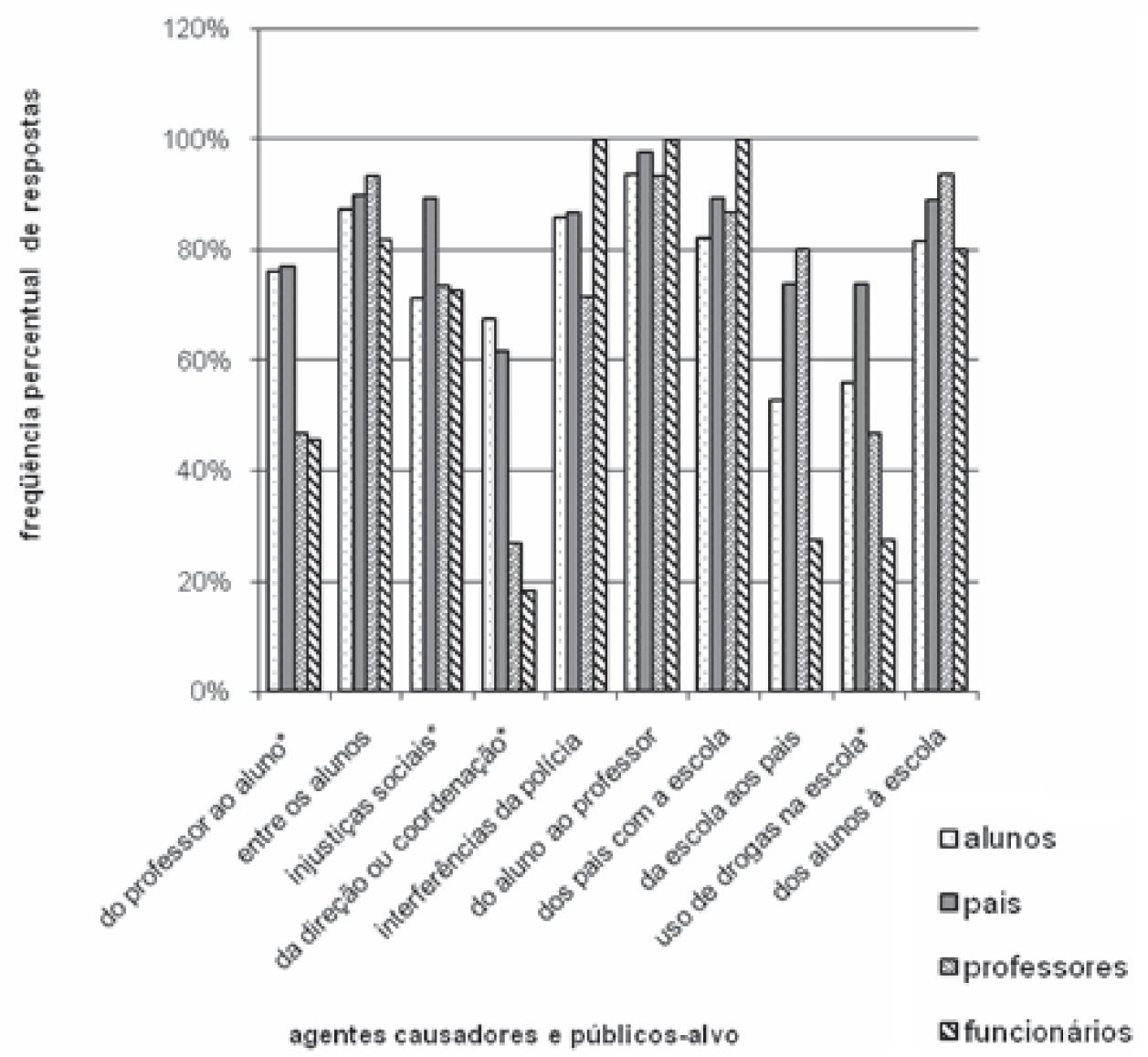

Figura I. Ocorrências de injustiça nas escolas

comportamento de alguns alunos; professor acusar, punir um aluno por algo que ele não fez; favoritismo do professor por alguns alunos; professor acusar, punir ou dar nota baixa a alunos por comportamento inadequado; professor xingar e/ou humilhar um aluno ou vários alunos. Todas essas situações podem ser consideradas graves e nocivas para o estabelecimento de uma relação de confiança e de reciprocidade entre o corpo docente, discente, técnico-administrativo e pais de alunos. Não se pode afirmar que esses acontecimentos realmente ocorrem, no entanto, não há como negar que essa é a forma como os alunos e pais os percebem, e que a mesma é muito discrepante daquela enxergada pelos professores e funcionários.

No que se refere às injustiças entre os alunos, não houve discordância significativa entre as amostras investigadas. A freqüência de ocorrência em cada categoria foi de: $87,2 \%$ dos alunos, $89,8 \%$ dos pais, $93,3 \%$ dos professores e $81,8 \%$ dos funcionários.
Os resultados deflagram, assim, a ocorrência de muitas injustiças entre os próprios alunos, e o reconhecimento dessa delicada realidade. São assinaladas situações que revelam relações carentes de respeito mútuo, que inspiram muita atenção e necessidade de intervenção, dentre elas: alunos tirarem vantagens ou prejudicarem outros alunos em trabalhos de grupo; alunos acusarem injustamente outros alunos por comportamento inadequado; violência física entre os alunos na escola, e alunos agindo com racismo.

No que diz respeito à identificação das injustiças sociais no âmbito educacional $\left(\chi^{2}=21,02 ; p<0,01\right)$, os pais de alunos foram os que mais as denunciaram $(89,2 \%)$, em seguida os professores $(73,3 \%)$ e os funcionários $(72,4 \%)$ e, por último, os alunos (7I\%). Houve disparidades entre as respostas, especialmente, conforme o tipo de injustiça situado. São os pais de alunos, especialmente, que mais denunciam a não garantia do direito das crianças à educação básica e o 
fato das classes sócio-econômicas mais favorecidas terem escola melhor porque podem pagar. Por outro lado, são os professores e funcionários que declaram a desvalorização salarial da classe docente.

Os dados sobre $a$ direção e/ou coordenação como agentes de injustiça $\left(\chi^{2}=21,4 ; p<0,01\right)$, e as diferenças entre as respostas conforme cada categoria participante foram significativas. Os alunos $(67,3 \%)$ e os pais de alunos $(6 \mathrm{I}, 5 \%)$ apontam, de forma muito mais intensa do que os professores $(26,7 \%)$ e funcionários (I8,2\%), as injustiças cometidas pela direção e coordenação. Os casos específicos em que essas discrepâncias se destacam são os seguintes: direção e coordenação não tomarem providências em relação à violência na escola; favoritismo da coordenação ou direção por alguns alunos; direção ou coordenação punir toda a classe devido ao comportamento de alguns alunos; a direção ou coordenação acusar ou punir aluno por comportamento inadequado por que não gosta do aluno; direção dar razão para professor mesmo quando ele está errado.

Esses dados se assemelham àqueles apresentados em relação às injustiças dos professores para com os alunos. Novamente, os alunos e os pais se sentem injustiçados e, os professores e funcionários não demonstram sensibilidade a essa realidade, inclusive, bastante prejudicial ao incitamento de relações mais cooperativas no ambiente escolar.

No que concerne às injustiças da polícia para com os alunos, esses casos revelam, com mais precisão, a necessidade de uma especial atenção à dinâmica das relações na escola investigada, uma vez que a maioria dos participantes, independente do papel desempenhado na escola $-85,9 \%$ dos alunos, $86,5 \%$ dos pais, 7I,4\% dos professores e $100 \%$ dos funcionários declara que, em diversas situações, a polícia tem que intervir para conter os comportamentos "inadequados" de alguns alunos. Podem ser levantadas duas hipóteses, que não são excludentes entre si: a primeira de que, realmente, as ocorrências são muito graves e oferecem riscos à integridade física dos membros da comunidade escolar, o que pode justificar a presença da Polícia Militar. E/ou a segunda, de que as relações estão tão fragilizadas que é necessário o uso de poder, ameaça e coação para o restabelecimento da or- dem do local. Esse é um assunto bastante complexo e delicado que, com certeza, precisa ser averiguado e enfocado em um programa interventivo. Não se pode deixar de destacar, entretanto, um dado positivo: a grande maioria dos participantes reconhece que a polícia não apresenta ações racistas e discriminatórias quando é chamada para intervir na escola.

Os dados que fazem menção às injustiças dos alunos em relação aos professores são: a maioria dos participantes de todas as categorias - alunos (93,6\%), pais $(97,5 \%)$, professores $(93,35 \%)$ e funcionários (100\%) - denuncia as injustiças dos alunos em relação aos professores. As situações consideradas são: alunos desrespeitarem ou brigarem com professor; alunos falarem mal do professor e alunos colarem. Esses dados, somados àqueles em que os alunos, também, são agentes de injustiças, só que voltados a outros públicos-alvos, indicam que há um descrédito geral em relação às atitudes dos alunos, inclusive, os próprios alunos confirmam essa condição.

Os itens relativos às injustiças dos pais com a escola e da escola com os pais demonstram a existência de eventuais e recíprocas reclamações dos pais em relação à escola e vice-versa. De forma geral, essa percepção é consensual, com exceção dos funcionários que indicam que há muito mais injustiças dos pais para com a escola ( $100 \%$ dos funcionários) do que da escola para com os pais ( $27,3 \%$ dos funcionários).

No que diz respeito ao uso de drogas lícitas e ilícitas na escola $\left(\chi^{2}=20,4 I ; p<0,0 I\right)$, fica patente a predominância da crença, entre a maioria dos pais (73,7\%), de que são utilizados diferentes tipos de substâncias psicoativas no ambiente escolar. Apesar da diferença entre as respostas dos pais de alunos e dos demais participantes - alunos (55,7\%), professores $(46,7 \%)$ e, em menor número, funcionários $(27,3 \%)$ - essas três últimas amostras, também, declaram que há a utilização de cigarros, por parte dos alunos, professores e funcionários, e de outras drogas na escola, no caso, por parte dos alunos.

Ao relacionar esses dados com as demais situações já mencionadas nos outros aspectos, constata-se que os pais, especialmente, e, em seguida, os próprios alunos, não percebem a escola como um local seguro, pois segundo a maioria deles: os alunos fumam nela; a 
direção e/ou coordenação não tomam providências em relação à violência na escola; os professores e funcionários fumam cigarro na escola, não dando o exemplo aos próprios alunos; há violência física entre os alunos; a polícia é chamada para coibir o aluno que está aprontando e, ainda, alunos utilizam drogas na escola.

No que concerne às injustiças dos alunos em relação à escola, a maioria dos participantes - alunos $(81,5 \%)$, pais $(88,9 \%)$, professores $(93,4 \%)$ e funcionários (80\%) - menciona a existência de situações em que os alunos não contribuem com a escola, principalmente, com a sua conservação física e de seus materiais. Novamente, aparece a incredulidade das pessoas partícipes da escola em relação ao corpo de estudantes. Na verdade, essa descrença revela o nãocrédito à função da escola em formar integralmente seus alunos, preparando-os para a socialização, ao mundo do trabalho, à vivência harmônica em comunidade e ao desenvolvimento de atitudes compostas por princípios de respeito, solidariedade, justiça, diálogo e cooperação.

Com base em Piaget (1932/1994) e Kohlberg (1976/ 1992), aponta-se que pode não estar sendo propiciada aos estudantes dessa instituição, o incentivo à construção da autonomia moral, do desenvolvimento de níveis morais mais elevados e, conseqüentemente, de uma noção ideal de justiça, baseada em princípios éticos universais, e caracterizada pela igualdade ou eqüidade da sanção e repartição igualitária entre direitos e deveres, e pelo reconhecimento da complexidade das circunstâncias locais, das necessidades e capacidades dos envolvidos, e da realidade social geral. Segundo esses autores, a autonomia moral só pode ser construída em um ambiente onde se propicie: o respeito mútuo; as relações de cooperação; a oportunidade de trocas de papéis; o contato com experiências que sejam desafiadoras e possibilitem conflitos cognitivos; o senso de responsabilidade; a motivação para o trabalho escolar; a confiança; o cuidado com a auto-estima, dentre outros aspectos.

Os resultados da presente pesquisa condizem com a afirmação de Menin (2003), de que, apesar da experiência de Kohlberg (1976/1992) e as idéias sobre escolas democráticas serem conhecidas, esse tipo específico de organização não condiz com o contexto escolar atual. Vão de encontro, também, com as pesquisas de Carbone e Menin (2004) e Shimizu e cols. (2003), nas quais a escola é percebida, pelos alunos, como espaço de injustiças diferentes e contínuas, sendo sua realidade muito diferente de uma comunidade justa.

Nas pesquisas analisadas por Carbone e Menin (2004) dois agentes principais de injustiças foram deflagrados: professores e alunos. Os professores foram concebidos como punindo, especialmente, com a utilização das notas como instrumento de poder, e os alunos por seus comportamentos, ou por serem desrespeitosos com os professores, ou acusando-os injustamente, ou ainda, nas relações entre si. As autoras, com base no resultado geral (houve diferenças entre os dois tipos de escolas investigadas - públicas e particulares-, cuja discussão não se insere no escopo do presente trabalho) questionam que valores morais estariam presentes, fundamentando as concepções e relações dos alunos com as normas escolares e, quais as possibilidades que os alunos têm de refletir sobre essas normas e sua incorporação pelos professores. De acordo com as autoras, as acusações dos alunos sobre as injustiças cometidas, especialmente, pelos professores, apontam para as representações que os alunos têm da escola, em que as normas e regras, na maioria das vezes, são impostas de maneira coercitiva e sem sua participação. A indisciplina tem sido um grande tema de discussão e queixa por parte dos professores, mas há a ausência de reflexões sobre as práticas de controle que têm sido utilizadas, e suas repercussões nessa mesma questão.

Esses estudos se reportaram, especificamente, à opinião dos alunos. Nossa pesquisa abrangeu os demais segmentos da escola, e identificou que a mesma é concebida como um espaço de inúmeras injustiças pelas diversas categorias de participantes da comunidade escolar. Os resultados deflagram as divergências de percepções sobre os supostos agentes e vítimas de injustiça, o que pode ser um fator muito prejudicial para a resolução dessas situações.

Curiosamente, os dados expostos revelam que os alunos estão mais atentos às circunstâncias atuais da escola e a percebem como um local que possui uma diversidade de problemas, especialmente, no que tan- 
ge às relações interpessoais. Nota-se, ainda, que são os alunos, e, depois, seus pais, que mais reconhecem que os problemas de relacionamento abrangem todos os segmentos da escola: corpo docente, administrativo, discente e pais de alunos. Diferentemente dos professores e funcionários, que concentram suas queixas, especialmente, em relação aos alunos.

Concordamos com a afirmação de Araújo (2002), de que a escola é um sistema complexo, e que a implementação de propostas, ainda, é um grande desafio e envolve uma diversidade de fatores que, perpassam desde os conteúdos escolares, a metodologia das aulas, até os valores dos membros da comunidade escolar e a maneira como as relações interpessoais se dão, dentre outros fatores.

Constata-se, também, que a atenção é voltada, predominantemente, apenas para a formação intelectual, deixando-se de lado a educação em valores morais. Isto é preocupante, uma vez que diferentes autores (Araújo, 1993; Buxarrais, 1997; Lepre, 200I; Menin, 1985, 2002b; Puig, 1998; Shimizu, 1998) defendem que em situações de ensino-aprendizagem, todos os professores, ainda que de forma implícita e não sistematizada, estão educando moralmente e em valores.

Conforme Buxarrais (1997) e Puig (1998), os diferentes modelos de Educação Moral e em valores são marcados, basicamente, por três tipos de concepções: o dogmatismo moral, no qual a educação está baseada em valores absolutos, inquestionáveis e imutáveis, que são colocados por um poder autoritário de forma coercitiva; o relativismo moral, em que as normas de conduta e os valores morais são considerados subjetivos e pessoais, não havendo um consenso sobre a melhor forma de agir e, os modelos baseados na construção racional e autônoma de valores, nos quais se busca o desenvolvimento de situações que facilitem a construção da autonomia do educando e a participação democrática dos vários membros da escola.

Em nível de Brasil, percebe-se como cada uma dessas concepções de Educação Moral - dogmática, relativista e dialógica - esteve presente em diferentes momentos históricos.

Fazendo uma retrospectiva a partir da década de 60, com base em Lepre (200I), observa-se que a Educação Moral esteve presente no ensino formal, em todos os graus e modalidades de ensino do País, como uma disciplina obrigatória curricular. Essa obrigatoriedade foi criada pelo Decreto-lei $n^{\circ} 869$, de 12 de junho de 1969, pelo Presidente Garrastazu Médici, na época da ditadura militar. Esse era um decreto de obediência, uma forma dogmática de condução da Educação Moral, marcada por uma matéria doutrinária e disciplinatória, que visava à promoção de uma ordem social vinculada aos ideais militares de controle e repressão da sociedade.

Após o fim da ditadura e com a tentativa de restabelecimento da democracia, em 1993, durante o governo de Itamar Franco, a obrigatoriedade de uma disciplina de Educação Moral no currículo escolar foi revogada pela lei 8.663 , de 14 de junho de 1996. Com isso, essa disciplina foi desaparecendo das escolas. Nota-se, também, que a experiência de se vivenciar a Educação Moral de forma dogmática e imposta, resultou na ausência de projetos pedagógicos explícitos e, até mesmo, de discussões sobre moral e valores no contexto escolar. Pode-se sugerir que, nesse momento, a predominância foi de uma concepção mais relativista e particularista de moral, na qual as decisões deveriam ser guiadas mais por parâmetros individuais do que coletivos.

Depois desse período significativo de silêncio, diante da urgência social impulsionada, principalmente, pelo aumento da violência e da indisciplina no meio escolar, e pela crise de valores morais que atingem a escola tanto em seus objetivos educacionais e procedimentos pedagógicos como nas relações entre seus membros, estudiosos voltam a levantar a necessidade de se educar moralmente, sendo elaborados, então, os Parâmetros Curriculares Nacionais (PCNs). No entanto, para concretização dessa proposta não basta discutir e refletir sobre valores, se faz necessário trabalhar para que a escola seja uma comunidade cada vez mais justa para que, assim, os membros da escola vivenciem a justiça e aprendam a serem justos.

O desafio ainda, é sua respectiva implantação e a necessidade de modificações urgentes na dinâmica relacional das escolas, e em especial, daquela focalizada em nosso estudo. Acredita-se, no entanto, que 
intervenções, nesse sentido, são necessárias e passíveis de realização, de acordo com o que foi verificado na literatura, principalmente, em Piaget (1930/ 1996, 1932/1994) e Kohlberg (1976/1992), e com base em demais autores, não detalhados neste texto (Aquino \& Araújo, 200I; Araújo, 2002, 2003, 2004; Puig, Martín, Escardíbul \& Novella, 2000; Zanatta, 2000), que apresentam propostas interventivas baseadas na construção racional e autônoma de valores, buscando-se o desenvolvimento da autonomia moral e de relações cooperativas por parte dos os membros da escola.

\section{Considerações Finais}

Constata-se, com esta pesquisa, que, muitas vezes, a percepção que se tem das situações injustas se diferencia, significativamente, entre os membros da comunidade escolar. De forma geral, os professores e funcionários reconhecem menos que as outras categorias ou não reconhecem injustiças, quando eles próprios são os agentes. O mesmo não ocorre com os alunos e seus pais, que admitem a ocorrência de injustiças, mesmo quando eles são considerados os agentes.

Os dados conduzem à hipótese inicial de que o tipo de respeito estabelecido nas relações entre os integrantes da escola, e o fato dessas relações serem consideradas justas ou injustas pelos atores nelas envolvidos, seja um fator importante na direção em que se dá o desenvolvimento moral dos membros da escola, e sobre a forma como eles se relacionam com as normas e regras escolares.

Pode-se verificar, a partir dos resultados apresentados, que a escola pesquisada necessita de uma intervenção eficaz, no sentido de propiciar relações mais justas no espaço escolar, que assegurem uma maior harmonia das mesmas, o respeito mútuo, a confiança e a autonomia das pessoas envolvidas.

Finaliza-se, apontando para a necessidade de desenvolvimento de mais estudos na área, enfocando os limites de generalização dos dados alcançados, levando em consideração as restrições inerentes à amostra participante na presente pesquisa.

\section{Referências}

Aquino, J. G., \& Araújo, U. F. (200I). Os direitos humanos na sala de aula: a ética como tema transversal. São Paulo: Moderna.

Araújo, U. F. A. (1993). Um estudo sobre as relações entre o ambiente cooperativo e o julgamento moral na criança. Dissertação de Mestrado, Universidade Estadual de Campinas, Campinas, São Paulo.

Araújo, U. F. (2002). A construção de escolas democráticas: histórias sobre complexidade, mudanças e resistência. São Paulo: Moderna.

Araújo, U. F. (2003). Temas transversais e a estratégia de projetos. São Paulo: Moderna.

Araújo, U. F. (2004). Assembléia escolar: um caminho para resolução de conflitos. São Paulo: Moderna.

Biaggio, A. M. B. (1997). Kohlberg e a "Comunidade Justa": promovendo o senso ético e a cidadania na escola. Psicologia Reflexão e Crítica, I0(I), 47-69 [On line]. Disponível: <http:// w w w. s c i e l o . c o m . b r / scielo.php?script =sci_arttext\&pid=S0I027972 | 997000 | 00005\&Ing=pt\&nrm=iso >. Recuperado: 10 Set. 2004.

Biaggio, A. M. B. (2002). Lawrence Kohlberg: ética e educação moral. São Paulo: Moderna.

Brasil. Ministério da Saúde. (1996). Conselho Nacional de Saúde. Resolução 196, de 10 de outubro de 1996. Aprova as diretrizes e normas regulamentadoras de pesquisa envolvendo seres humanos. Brasília, DF.

Brasil. MEC. (1997). Secretaria de Educação Fundamental. Parâmetros Curriculares Nacionais: primeiro e segundo ciclos do Ensino Fundamental. Brasília: MEC/SEF.

Brasil. MEC. (1998). Secretaria de Educação Fundamental. Parâmetros Curriculares Nacionais: terceiro e quarto ciclos do Ensino Fundamental. Brasília: MEC/SEF.

Buxarrais, M. R. (1997). Un modelo de curso para la formación permanente en Educación en valores. Em M. R. Buxarrais (Org.), La formación del professorado en educación en valores. Propuesta y materiais (pp. 7I-108). Bilbao: Editorial Desclée de Brouwer.

Carbone, R. A., \& Menin, M. S. S. (2004). Injustiça na escola: representações sociais de alunos do ensino fundamental e médio. Educação e Pesquisa, 2(30), 25 I-257. 
Kohlberg, L. (1992). Estadios morales y moralización: la via cognitiva evolutiva (A. Z. Zárate, Trad.). Em L. Kohlberg (Org.), Psicologia del desarrollo moral (pp. I85-2।4).Bilbao: Editorial Desclée de Brouwer. (Trabalho original publicado em 1976)

Kohlberg, L., Power, F. C., \& Higgins, A. (1997). La Educación Moral Segundo Lawrence Kohlberg (A. Bonnano, Trad.). Barcelona: Editorial Gedisa. (Trabalho original publicado em 1989)

Lepre, R. M. (200I). A indisciplina na escola e os estágios de desenvolvimento moral na teoria de Jean Piaget. Dissertação de Mestrado em Educação, Universidade Estadual Paulista, Marília, São Paulo.

Menin, M.S. S. (1985). Autonomia e heteronomia às regras escolares: observações e entrevistas na escola. Dissertação de Mestrado, Universidade de São Paulo, São Paulo, São Paulo.

Menin, M. S. S. (2000). Representações sociais de lei, crime e injustiça em adolescentes. Tese de Livre-Docência, Universidade Estadual Paulista, Presidente Prudente, São Paulo.

Menin, M. S. S. (2002a). Representações sociais de injustiça em adolescentes de escolas públicas e particulares. Psicologia da Educação, (I4/I5), 239-264.

Menin, M. S. S. (2002b). Valores na escola. Revista Educação e Pesquisa, 28(I), 9I-I00 [On-line]. Disponível: <http:// www.scielo.com.br/scielo.php?script $=$ sci_arttext\&pid $=$ SI 5 I 797022002000 $100006 \&$ Ing=pt\&nrm=iso $>$. Recuperado: 10 set. 2004.

Menin, M. S. S. (2003). Escola: comunidade justa? (Trabalho completo). Em Programa de Educação Infantil e Ensino Fundamental
(Org.), Anais, XX Encontro Nacional de Professores do PROEPRE (pp. I I I-I I8). Águas de Lindóia: PROEPRE.

Piaget, J. (1 994). O juízo moral na criança. São Paulo: Summus. (Trabalho original publicado em 1932)

Piaget, J. (1996). Os Procedimentos da Educação Moral. Em L. Macedo (Org.), Cinco estudos de Educação Moral (pp. I-36). São Paulo: Casa do Psicólogo. São Paulo: Casa do Psicólogo. (Trabalho original publicado em 1930)

Puig, J. M. (1998). Ética e valores: métodos para um ensino transversal. São Paulo: Casa do Psicólogo.

Puig, J. M., Martín, X., Escardíbul, S., \& Novella, A. N. (2000). Democracia e participação escolar: propostas de atividades. São Paulo: Moderna.

Shimizu, A. M. (1998). As representações sociais de moral de professores das quatro primeiras séries do ensino de $1^{\circ}$ grau. Dissertação de Mestrado, Universidade Estadual Paulista, Marília, São Paulo.

Shimizu, A. M., Menin, M. S. S., Cordeiro, A. P., Spada, A. C. M., Oliveira, C. A. V., Souza, E. F. D., Belão, V. K., Osório, W. G., \& Costa, M. L. A. (2003). Injustiças na escola: concepções de alunos do Ensino Fundamental e Médio. Relatório da pesquisa realizada junto ao Programa de Absorção Temporária de Doutores - Prodoc, CAPES. Faculdade de Ciência e Tecnologia, Universidade Estadual Paulista, Campus de Presidente Prudente.

Zanatta, A. A. (2000). Oficinas pedagógicas de direitos humanos. Petrópolis: Vozes.

Recebido em: 28/09/2006

Revisado em: 30/10/2007

Aprovado em: 17/12/2007

Sobre as autoras

Thaise Belucil - Acadêmica do curso de Psicologia da Faculdade de Ciências da Saúde de Garça

E-mail para contato: thaisebeluci@gmail.com

Endereço: Avenida Paulista, II 04 - Gália / SP - CEP: I7450-000

Fone: (I4) 3274-1514 / (14) 9734-3009

Alessandra de Morais Shimizu - Psicóloga, Doutora em Educação e Professora do curso de Psicologia da Faculdade de Ciências da Saúde de Garça E-mail para contato: ashimizu@flash.tv.br

Endereço: Rua Angelo Marconi, 255 - Marília / SP - CEP: 17516-680

Fone: (I4) 3422-5570 / (14) $9601-018$ I

I Pesquisa de Iniciação Científica financiada pela Fundação de Amparo à Pesquisa do Estado de São Paulo (FAPESP). 